\title{
Ca-Zn (Calcium-Zinc)
}

\section{H. Okamoto}

The Ca-Zn phase diagram in [Massalski2] was as assessed by [1990Itk] mainly based on the extensive DTA work done by [1963Mes]. $\mathrm{Ca}_{7} \mathrm{Zn}_{4}$ and $\mathrm{Ca}_{7} \mathrm{Zn}_{20}$ were modified to $\mathrm{Ca}_{5} \mathrm{Zn}_{3}$ and $\mathrm{CaZn}_{3}$, respectively, based on later reports on crystal structures. No experimental phase diagrams have been reported on this system after [1990Itk]. Nevertheless, [1990Itk], [2001Bru], [2008Spe], and [2009Was] thermodynamically assessed the data of [1963Mes]. All calculated phase diagrams are in good agreement with the data of [1963Mes]. Figure 1 shows the most recent result of [2009Was].

\section{References}

1963Mes: A.F. Messing, M.D. Adams, and R.K. Steunenberg, Contribution to the Phase Diagram Calcium-Zinc, Trans. ASM, 1963, 56, p 345-350
1990Itk: V.P. Itkin and C.B. Alcock, The Ca-Zn (CalciumZinc) System, Bull. Alloy Phase Diagrams, 1990, 11(4), p 328-333

2001Bru: C.O. Brubaker and Z.K. Liu, A Computational Thermodynamic Assessment of the Ca-Zn System. Calphad, 2002, 25(3), p 381-390

2008Spe: P.J. Spencer, A.D. Pelton, Y.B. Kang, P. Chartrand, and C.D. Fuerst, Thermodynamic Assessment of the Ca-Zn, Sr-Zn, Y-Zn, and Ce-Zn Systems. Calphad, 2008, 32, p 423431

2009Was: S. Wasiur-Rahman and M. Medraj, Critical Assessment and Thermodynamic Modeling of the Binary Mg-Zn, Ca$\mathrm{Zn}$ and Ternary Mg-Ca-Zn Systems. Intermetallics, 2009, 17, p $847-864$

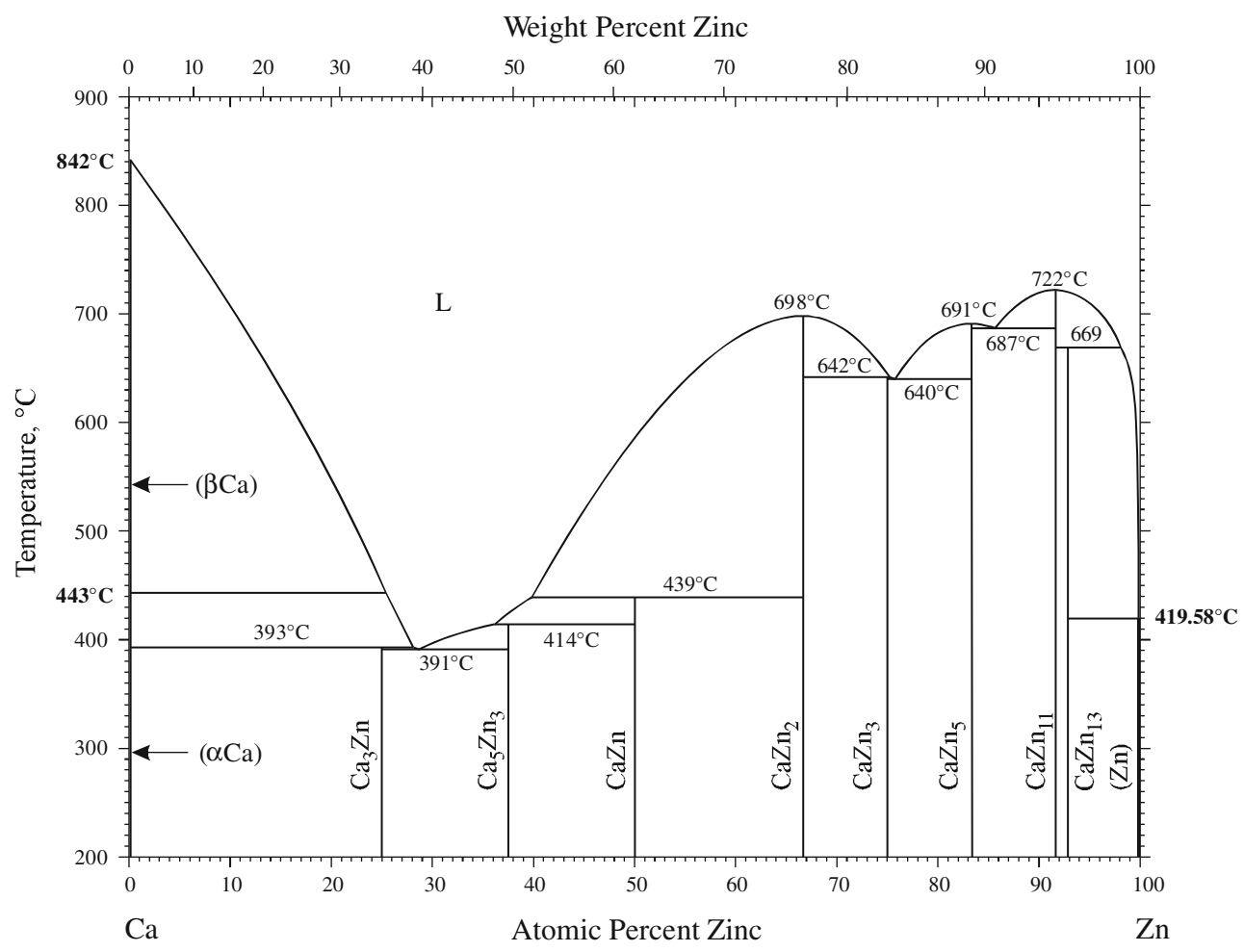

Fig. 1 Ca-Zn phase diagram from [2009Was] 